\title{
What do young adults know about the HIVIAIDS epidemic? Findings from a population based study in Karachi, Pakistan Syed Farid-ul-Hasnain*1,2, Eva Johansson ${ }^{2,3}$ and Gunilla Krantz ${ }^{2,4}$
}

\author{
Address: ${ }^{1}$ Department of Community Health Sciences, Aga Khan University, Karachi, Pakistan, ${ }^{2}$ Department of Public Health Sciences, Division \\ of Global Health, IHCAR, Karolinska Institutet, Stockholm, Sweden, ${ }^{3}$ Nordic School of Public Health, Gothenburg, Sweden and ${ }^{4}$ Dept of \\ Community Medicine and Public Health, The Sahlgrenska Academy at University of Gothenburg, Gothenburg, Sweden \\ Email: Syed Farid-ul-Hasnain* - farid.hasnain@aku.edu; Eva Johansson - Eva.Johansson@ki.se; Gunilla Krantz - gunilla.krantz@socmed.gu.se \\ * Corresponding author
}

Published: 26 March 2009

BMC Infectious Diseases 2009, 9:38 doi:10.1 186/1471-2334-9-38
Received: 29 October 2008

Accepted: 26 March 2009

This article is available from: http://www.biomedcentral.com/I47/-2334/9/38

(C) 2009 Farid-ul-Hasnain et al; licensee BioMed Central Ltd.

This is an Open Access article distributed under the terms of the Creative Commons Attribution License (http://creativecommons.org/licenses/by/2.0), which permits unrestricted use, distribution, and reproduction in any medium, provided the original work is properly cited.

\begin{abstract}
Background: HIVAIDS is spreading globally, hitting the younger generations. In Pakistan, the prevalence of HIV in high-risk subpopulations is five per cent or higher. This poses a serious threat of a generalised epidemic especially among the younger population. In the wake of HIVAIDS epidemic this is worrying as a well informed younger generation is crucial in restricting the spread of this epidemic. This study investigated Pakistani young adults' (male and female) knowledge and awareness of the HIVIAIDS disease.
\end{abstract}

Methods: A population-based, cross-sectional study of I,650 male and female adults aged 17-2I years living in Karachi was conducted using a structured questionnaire. A multi-stage cluster sampling design was used to collect data representative of the general population in an urban area. Bivariate and multivariate analyses were performed separately for males and females.

Results: Of I,650 subjects, 24 per cent $(n=390)$ reported that they had not heard of HIV/AIDS. Among the males, those with a poor knowledge were younger $(\mathrm{AOR}=2.20$; 95 per cent $\mathrm{Cl}, \mathrm{I} .38$, 3.49), with less than six years of schooling $(A O R=2.46 ; 1.294 .68)$ and no computer at home (AOR $=1.88 ; 1.063 .34)$. Among the females, the risk factors for poor knowledge were young age (AOR $=1.74 ; 1.22,2.50)$, low socio-economic status $(A O R=1.54 ; 1.06,2.22)$, lack of enrolment at school/college $(A O R=1.61 ; 1.09,2.39)$ and being unmarried $(A O R=1.85 ; 1.05,3.26)$.

Conclusion: Alarming gaps in knowledge relating to HIVIAIDS were detected. The study emphasises the need to educate young adults and equip them with the appropriate information and skills to enable them to protect themselves from HIVIAIDS. However, taboos surrounding public discussions of sexuality remain a key constraint to preventive activities.

\section{Background}

Young people aged 15-24 account for an estimated 45\% of new HIV infections worldwide [1]. Even though the present prevalence of HIV is comparatively low in many Asian countries, epidemics in Indonesia, Pakistan, and Vietnam are growing rapidly [1]. Alarming gaps in knowl- edge relating to the HIV/AIDS epidemic among young adults are frequently reported $[2,3]$.

According to UNAIDS estimates, the prevalence of HIV/ AIDS among the population of men and women aged 1524 in Pakistan is about 0.1 per cent [1]. Surveillance data 
from the Sindh provincial AIDS control programme indicate that the country has, however entered the "concentrated epidemic" stage for HIV/AIDS, in the sense that the HIV prevalence in high-risk subpopulations is five per cent or higher $[4,5]$. These high-risk subpopulations are injecting drug user communities and commercial sex networks in larger cities in Pakistan [6,7]. This poses a serious threat of a generalised epidemic, especially among the younger population $[4,5]$.

Between 1981 and 2000, the mean age at marriage in Pakistan rose from 25.1 to 26.3 years for males and 20.2 to 22.1 years for females [8]. This indicates a widening window during which young people are likely to engage in risky sexual behaviour. The estimated population of adolescents (10-19 years of age) in Pakistan is over 30 million, which is approximately 23 per cent of the total population [9].

Youth populations are likely to engage in high-risk sexual behaviour. In those low-income countries where males are assigned a higher social status than females, it is mostly put on young women's shoulders to protect themselves from sexually transmitted infections and unwanted pregnancies but at the same time they often lack access to appropriate information about contraceptives and have poor access to relevant services for prevention and treatment [10-12].

Access and exposure to appropriate HIV/AIDS information and discussing it with others has the potential positively to impact knowledge, attitudes, beliefs and sexual practices [13]. Still, youth populations are poorly informed in Pakistan due to limited access to information about sexual and reproductive health matters, as both parents and the school system are reluctant to fulfil this obligation due to the sensitivity of the subject $[14,15]$. On the other hand, younger population obtain this information through the media, such as TV and the internet [16], but relying on such sources of information for the nation's younger generations is not advisable. Considering this, and the fact that the HIV/ AIDS epidemic is on the increase in Pakistan makes it extremely important to assess young people's knowledge and perceptions of sexual and reproductive health matters and of the HIV/AIDS epidemic in particular to identify knowledge gaps for further preventive activities.

This population-based study assessed the level of knowledge and awareness of the HIV/AIDS epidemic among young adults, aged 17-21 years, in Karachi, Pakistan, focusing on modes of spread and preventive measures. Males and females were compared and particular risk groups were identified.

\section{Methods}

\section{Population}

This population-based, cross-sectional study of young adults aged 17-21 years was conducted in the metropoli- tan city of Karachi, where the population consists of several ethnic groups from all areas of the country. The sample size was calculated at a total of 1,650 with the assumption that 50 and 57 per cent of the males and females respectively would have insufficient knowledge of the modes of spread of HIV/AIDS [17,18], applying a 95 per cent confidence level, a power of 80 per cent and including an equal number of males and females. The sample size was also calculated while incorporating the element of design effect. The data collection was carried out between June and August 2006.

\section{Sampling}

A multi-stage cluster sampling design was used to identify the respondents. The city of Karachi comprises 18 towns (administrative units), further divided into union councils. The calculated sample size $(1,650)$ was then divided in proportion to the population size of the towns, as reported in the last census of 1998. One union council from each of the towns was randomly selected and further divided into blocks, each comprising 50 households. Proportionate numbers of blocks were chosen at random from the list of all the given blocks. Finally, 10 eligible households with one or more persons aged 17-21 years were chosen using systematic sampling (every fifth household from a total of 50 households in the selected block). In all, 165 blocks were chosen and, by taking 10 households from each block, the desired sample size was reached.

If there was more than one eligible person in the household, one was randomly chosen. Equal numbers of males and females were selected. There were $10-15$ per cent refusals in some of the blocks. This was taken into account by moving to the next household until the desired sample was obtained.

A questionnaire based on existing validated instruments from national surveys of reproductive health of youth in Pakistan was used $[18,19]$, but it was supplemented with context-specific items to assess the knowledge and awareness of behaviours related to HIV/AIDS. The questionnaire also contained items on socio-demographic and psychosocial conditions. The same questionnaire was used for males and females and was pre-tested prior to the data collection.

The data were collected by a team of male and female interviewers of about the same age as the male and female respondents in order to facilitate communication. The interviews were conducted at their homes, ensuring that no other person could overhear the conversation. Six interviewers (three males and three females) were trained at a two-day workshop (classroom discussion sessions) to ensure a full understanding of the instrument and its purpose. The training was conducted by the principal investi- 
gator, supported by a field manager and a field supervisor, who together developed the instruction manual for the interviewer training.

\section{Dependent variable}

Two open-ended questions assessed knowledge of HIV/ AIDS; one on the modes of spread phrased 'What are the various modes by which HIV/AIDS is being spread' and the other on preventive strategies phrased 'Name a few strategies using which an individual can prevent himself/ herself from getting infected with HIV/AIDS'. The responses were assessed as 'correct' or 'incorrect' by the researchers. Each of the two variables was then coded into four categories, i.e. 'poor knowledge' (no correct answer), 'some knowledge' (1 correct answer), 'good knowledge' (2 correct answers) and 'very good knowledge' (3 or more correct answers). A composite variable based on the two items was created and defined at three levels, i.e. 'poor knowledge' (both variables had only incorrect responses), 'some knowledge' (exactly one variable had at least one correct response) and 'good knowledge' (both variables had at least one correct response). For multivariate analyses, the composite variable was dichotomised into 'poor knowledge' as opposed to 'some knowledge' and 'good knowledge' taken together.

\section{Independent variables}

Socio-economic status (SES) was based on the possession of assets by the households. Initially, an average current price in the market was assigned to the various assets and scores were developed on the basis of their values. Socioeconomic status was dichotomised at the median (Rs.20, 000/- equal to US\$340/-) into medium to high as opposed to low SES. As total monthly income was reported by only 23 per cent of the study subjects, it could not be used.

Age was classified into two groups; $17-18$ and 19-21 years of age. Educational level was based on the number of years of education and dichotomised into those with $\geq 6$ years of schooling and $<6$ years. Enrolment at school/college was classified as enrolled or not enrolled. Working status was defined as those in paid employment/voluntary work as opposed to those not in paid employment/voluntary work, including students. Marital status was defined as ever married or unmarried. Residential status was classified as permanent or migrant; those ethnic groups who were native to the city of Karachi at the time of independence (1947), including the migrants from India, were classified as permanent. Family type was dichotomised into 'nuclear families' (living with their children only) as opposed to 'extended families' (grandparents, grandchildren or in-laws also living as household members).

\section{Statistical procedures}

Cronbach's alpha coefficient was used to measure the internal consistency of the items defining the dependent variable, knowledge of HIV/AIDS; it was 0.75. Odds ratios were used to estimate bivariate associations between socio-demographic and psychosocial factors and knowledge of HIV/AIDS. Multiple logistic regression analyses further identified different tentative models of association and possible confounding factors. Only those variables that displayed statistically significant associations in the bivariate analyses were entered stepwise. Marital status was only marginally significant in the bivariate analysis for females, but it was included in the logistic regression models due to its inherent importance. All the analyses were performed separately for males and females.

The data were double entered into Epi Info version 6.04d [17]. Ten per cent of the questionnaires were checked randomly to look for any error in the data entry. SPSS version 15.0 [20] was used for the data analysis.

\section{Ethical considerations}

Ethical approval for the study was obtained from the Aga Khan University Ethical Review Committee (AKU-ERC). Informed consent was obtained both from the parents and from the respondents. Due to the sensitivity of reproductive health matters among youth in Pakistan's social context, great care was taken in training the interviewers not to cause any argument or controversy while approaching the respondents.

\section{Results}

Average life circumstances in the study population differed for males and females. More females belonged to the migrant group and more females also lived in an extended family setting, had a lower socio-economic status and reported not being in paid employment as compared to the males (Table 1). Only 7.2 per cent of the participants were married and they were mainly females. Access to TV was higher among females (93.7 per cent) than males (86.4 per cent), while more males ( 25.7 per cent) than females (18.1 per cent) had access to computers (Table 1 ).

\section{'Not heard' of HIVIAIDS}

Of the total population of 1,650 adolescents, 390 reported that they had not heard of HIV/AIDS, i.e. 221 (26.8 per cent) males and 169 (20.5 per cent) females.

Due to the relatively high proportion of young people who were ignorant on HIV, analyses were made to compare those who had not heard of HIV/AIDS $(n=390)$ with those who had some knowledge $(n=1260)$. The males who had not heard of HIV/AIDS were less well educated in that 76.0 per cent had $\geq 6$ years of school/college, as compared to 89.4 per cent $(p<0.001)$ among those reporting a knowledge of $\mathrm{HIV}$, and had less access to computers (13.1 per cent vs 30.2 percent; $\mathrm{p}<0.001$ ). Similarly, the females who had not heard of HIV/AIDS were less well educated (68.6 per cent as compared to 82.6 per 
Table I: Socio-demographic and psychosocial characteristics, $n=1,650$ (

\begin{tabular}{|c|c|c|c|c|c|c|}
\hline \multirow[t]{2}{*}{ Characteristic } & \multicolumn{2}{|c|}{ All } & \multicolumn{2}{|c|}{ Males } & \multicolumn{2}{|c|}{ Females } \\
\hline & $\mathbf{n}$ & $\%$ & $\mathbf{n}$ & $\%$ & $\mathbf{n}$ & $\%$ \\
\hline \multicolumn{7}{|l|}{ Age (years) } \\
\hline $17-18$ & 685 & 41.5 & 339 & 41.0 & 346 & 42.0 \\
\hline$|9-2|$ & 965 & 58.5 & 487 & 59.0 & 478 & 58.0 \\
\hline \multicolumn{7}{|l|}{ Educational level } \\
\hline Illiterate & 174 & 10.5 & 71 & 8.6 & 103 & 12.5 \\
\hline Can read a newspaper & 3 & 0.2 & 0 & 0.0 & 3 & 0.4 \\
\hline Can read a newspaper and write a letter & I & 0.1 & 0 & 0.0 & I & 0.1 \\
\hline I-5 years of schooling & 106 & 6.4 & 46 & 5.6 & 60 & 7.3 \\
\hline $6-10$ years of schooling & 998 & 60.5 & 537 & 65.0 & 461 & 55.9 \\
\hline $11-12$ years of school/college & 317 & 19.2 & 152 & 18.4 & 165 & 20.0 \\
\hline$>12$ years of school/college & 51 & 3.1 & 20 & 2.4 & 31 & 3.8 \\
\hline \multicolumn{7}{|l|}{ Years of schooling } \\
\hline$<6$ & 284 & 17.2 & 117 & 14.2 & 167 & 20.2 \\
\hline$\geq 6$ & 1366 & 82.8 & 709 & 85.8 & 657 & 79.8 \\
\hline \multicolumn{7}{|l|}{ Current enrolment in school/college } \\
\hline Yes & 811 & 49.2 & 473 & 57.3 & 338 & 41.0 \\
\hline No & 839 & 50.8 & 353 & 42.7 & 486 & 59.0 \\
\hline \multicolumn{7}{|l|}{ Current working status } \\
\hline Student & 824 & 49.9 & 476 & 57.6 & 348 & 42.2 \\
\hline Staying at home/Housewife & 310 & 18.8 & 0 & 0.0 & 310 & 37.6 \\
\hline Unemployed & 253 & 15.3 & 153 & 18.5 & 100 & 12.1 \\
\hline Paid job & 189 & 11.5 & 155 & 18.8 & 34 & 4.1 \\
\hline Self employed & 44 & 2.7 & 36 & 4.4 & 8 & 1.0 \\
\hline Volunteer work & 30 & 1.8 & 6 & 0.7 & 24 & 2.9 \\
\hline \multicolumn{7}{|l|}{ Occupational status } \\
\hline Non working (including student) & 1387 & 84.1 & 629 & 76.1 & 758 & 92.0 \\
\hline Working & 263 & 15.9 & 197 & 23.9 & 66 & 8.0 \\
\hline \multicolumn{7}{|l|}{ Marital status } \\
\hline Unmarried & 1532 & 92.8 & 823 & 99.6 & 709 & 86.0 \\
\hline Ever married & 118 & 7.2 & 3 & 0.4 & 115 & 14.0 \\
\hline \multicolumn{7}{|l|}{ Residential status } \\
\hline Permanent & $|13|$ & 68.5 & 604 & 73.1 & 527 & 64.0 \\
\hline Migrant & 519 & 31.5 & 222 & 26.9 & 297 & 36.0 \\
\hline \multicolumn{7}{|l|}{ Family setup } \\
\hline Extended & 333 & 20.2 & 48 & 5.8 & 285 & 34.6 \\
\hline Nuclear & 1317 & 79.8 & 778 & 94.2 & 539 & 65.4 \\
\hline \multicolumn{7}{|l|}{ Socio Economic Status. } \\
\hline High to middle & 697 & 42.2 & 364 & 44.1 & 333 & 40.4 \\
\hline Low & 953 & 57.8 & 462 & 55.9 & 491 & 59.6 \\
\hline \multicolumn{7}{|l|}{ Television in the home } \\
\hline Yes & 1486 & 90.1 & 714 & 86.4 & 772 & 93.7 \\
\hline No & 164 & 9.9 & 112 & 13.6 & 52 & 6.3 \\
\hline \multicolumn{7}{|l|}{ Computer in the home } \\
\hline Yes & 361 & 21.9 & 212 & 25.7 & 149 & 18.1 \\
\hline No & 1289 & 78.1 & 614 & 74.3 & 675 & 81.9 \\
\hline
\end{tabular}


cent; $\mathrm{p}<0.001)$, more frequently belonged to a family with low socio-economic status (76.9 per cent vs 55.1 per cent; $\mathrm{p}<0.001$ ) and fewer were married (12.4 per cent vs 14.4 per cent; $\mathrm{p}$ 0.52) as compared to those reporting a knowledge of HIV/AIDS.

\section{Knowledge and awareness of HIV}

Varied responses were noted for knowledge and awareness among the 1,260 reporting knowledge of HIV. A screening question inquiring about whether or not HIV/ AIDS is curable revealed that only 32 per cent of the males but 55 per cent of the females gave a correct 'no' response to this question. However, almost twice as many females (28.1 per cent) as males (15.4 per cent) reported that they did not know how the HIV/AIDS virus is spread (Table 2).

Of the males, 70.7 per cent reported sexual contact as a mode of spread, as did 44.4 per cent of the females. A difference was noted for 'used syringe' and 'HIV/AIDS-positive blood infusion', where substantially more females than males believed these contributed to the spread of HIV/AIDS (Table 2). Nevertheless, misconceptions were also identified, such as talking, shaking hands, coughing or eating with an HIV/AIDS-infected person. These misconceptions were more common among the females (Table 2).

Regarding ways of preventing the further spread of HIV/ AIDS, 34.7 per cent of the females and 41.3 per cent of the males reported having no knowledge of preventive measures (Table 3). Further, 41.3 per cent of the males and 32.4 per cent of the females reported avoidance of sex as a preventive measure, but, when the females and males who also mentioned avoiding 'extramarital sex' were added together, the difference was smaller (Table 3). Here, too, substantially more females than males appeared to be aware of blood contamination as a mode of spread (Table 3).

In the next step, the level of knowledge was categorised as very good, good, some or poor knowledge, depending on of the number of the suggested measures that were classified as correct. Almost twice as many females as males were categorised as having poor knowledge of the modes of spread for HIV/AIDS, but, on the other hand, females considerably outnumbered males in the 'very good' knowledge category. For preventive strategies, the females were more knowledgeable than the males and statistically significant differences were found between females and males at all knowledge levels, as presented in Figure 1 and 2.

Figure 3, which shows the summarised variable, reveals that more females than males had a 'good knowledge' (61.6 and 56.7 per cent respectively), while substantially more females than males also displayed a 'poor knowledge' of HIV/AIDS (27.9 and 14.7 per cent respectively).

Risk factor analysis using the summarised knowledge variable revealed that, in the case of males, young age (17-18 years) (crude odds ratio, $\mathrm{COR}=2.16 ; 95 \%$ confidence interval, CI, 1.37, 3.40), less than six years of schooling $(\mathrm{COR}=2.84 ; 1.57,5.14)$, migrant residential status (COR $=1.68 ; 1.03,2.72$ ) and no computer in the household $(\mathrm{COR}=2.0 ; 1.15,3.52)$ were associated with poor knowledge (Table 4$)$. Young age (17-18 years) was also significantly associated with a poor knowledge of HIV/AIDS among the females $(\mathrm{COR}=1.72 ; 1.22,2.44)$, as was a lack of enrolment at school/college $(\mathrm{COR}=1.43 ; 1.01,2.04)$ and low socio-economic status $(\mathrm{COR}=1.71 ; 1.20,2.43)$, (Table 4).

Table 2: Suggestions for modes of spread of HIVAIDS among males and females, $n=1,260$ ( males $=605$, females $=655$ )

\begin{tabular}{|c|c|c|c|c|c|c|}
\hline \multirow[t]{2}{*}{ FACTORS } & \multicolumn{2}{|c|}{ All } & \multicolumn{2}{|c|}{ Males } & \multicolumn{2}{|c|}{ Females } \\
\hline & $\mathbf{n}$ & $\%$ & $\mathbf{n}$ & $\%$ & $\mathbf{n}$ & $\%$ \\
\hline Sexual contact & 719 & 57.1 & 428 & 70.7 & 291 & 44.4 \\
\hline Re-used syringe & 306 & 24.3 & 48 & 7.9 & 258 & 39.4 \\
\hline HIV/AIDS-positive blood infusion & 195 & 15.5 & 44 & 7.3 & 151 & 23.1 \\
\hline Used blade/razor & 56 & 4.4 & 19 & 3.1 & 37 & 5.6 \\
\hline HIVIAIDS-positive mother to newborn transmission & 40 & 3.2 & 10 & 1.7 & 30 & 4.6 \\
\hline Nose/ear piercing and grafting names on skin & 6 & 0.5 & 0 & 0 & 6 & 0.9 \\
\hline Improperly cleaned operative instruments & 7 & 0.6 & 0 & 0 & 7 & 1.1 \\
\hline Eating with HIVIAIDS-positive patient & 14 & 1.1 & 0 & 0 & 14 & 2.1 \\
\hline Coughing from HIVIAIDS-positive patient & 3 & 0.2 & 1 & 0.2 & 2 & 0.3 \\
\hline Talking to HIV/AIDS-positive patient & 3 & 0.2 & 1 & 0.2 & 2 & 0.3 \\
\hline Shaking hands with HIVIAIDS-positive patient & 9 & 0.7 & I & 0.2 & 8 & 1.2 \\
\hline Uncleanliness & 37 & 2.9 & 0 & 0 & 37 & 5.6 \\
\hline Other & 27 & 2.1 & 3 & 0.6 & 24 & 3.7 \\
\hline Don't know & 277 & 22 & 93 & 15.4 & 184 & 28.1 \\
\hline
\end{tabular}

\footnotetext{
* Multiple responses
} 
Table 3: Suggestions for preventive strategies regarding HIVIAIDS among males and females, $n=I, 260($ males $=605$, females $=655)$.

\begin{tabular}{|c|c|c|c|c|c|c|}
\hline \multirow[t]{2}{*}{ FACTORS } & \multicolumn{2}{|c|}{ All } & \multicolumn{2}{|c|}{ Males } & \multicolumn{2}{|c|}{ Females } \\
\hline & $\mathbf{n}$ & $\%$ & $\mathbf{n}$ & $\%$ & $\mathbf{n}$ & $\%$ \\
\hline Avoiding sex & 462 & 36.7 & 250 & 41.3 & 212 & 32.4 \\
\hline Using new syringe & 159 & 12.6 & 38 & 6.3 & 121 & 18.5 \\
\hline Avoiding extramarital sexual contacts & $|3|$ & 10.4 & 41 & 6.8 & 90 & 13.7 \\
\hline Using screened blood & 92 & 7.3 & 2 & 0.3 & 90 & 13.7 \\
\hline Avoiding used blade/razor for shaving & 46 & 3.7 & 29 & 4.8 & 17 & 2.6 \\
\hline Faithful only to marital partner & 22 & 1.7 & 7 & 1.2 & 15 & 2.3 \\
\hline Avoiding use of items of HIVIAIDS patient & 8 & 0.6 & I & 0.2 & 7 & 1.1 \\
\hline Avoiding grafting names on skin & 3 & 0.2 & 0 & 0 & 3 & 0.5 \\
\hline Other & 25 & 2.3 & 5 & 1.3 & 18 & 3.1 \\
\hline Don't know & 477 & 37.9 & 250 & 41.3 & 227 & 34.7 \\
\hline
\end{tabular}

* Multiple responses

The multivariate analyses were performed separately for males and females to explore possible confounding factors and chains of associations. For the males, all the variables apart from migrant residential status remained statistically significant in the final model (Table 5). For the females, young age, low SES and no enrolment at school were identified as risk factors for a poor knowledge of HIV/AIDS, but this also applied to being unmarried $(\mathrm{AOR}=1.85 ; 1.05,3.26)$, although marital status was marginally significant in the bivariate analysis (Table 4). There were no correlations exceeding 0.4 between independent variables in any of the models (Cramer's V).

\section{Discussion}

This study found serious gaps in knowledge and awareness among young Pakistanis, aged 17 to 21 , regarding the

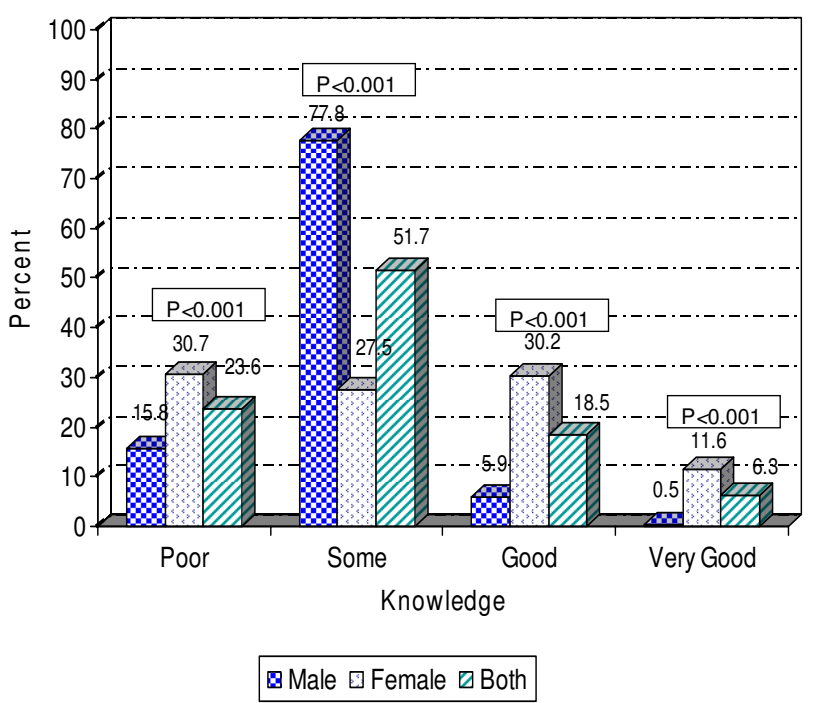

Note: $P$-value (z-test for difference in proportion between males and females at different knowledge levels)

Figure I

Knowledge level of modes of spread of HIVIAIDS by sex, $n=1,260$ (males $=605$, females $=655)$. modes of spread and ways of preventing the further transmission of the HIV/AIDS virus. It is most worrying that, when those in the 'poor knowledge' category were added to those who had not heard about HIV/AIDS, 38 per cent of the males and 43 per cent of the females from the total population in this study were ignorant about HIV. These young people were mainly found in lower socio-economic strata.

A substantial percentage of males and of females who had heard about HIV/AIDS were, however, not knowledgeable about HIV being an incurable disease, the way HIV is spread or ways of preventing the further spread. Among

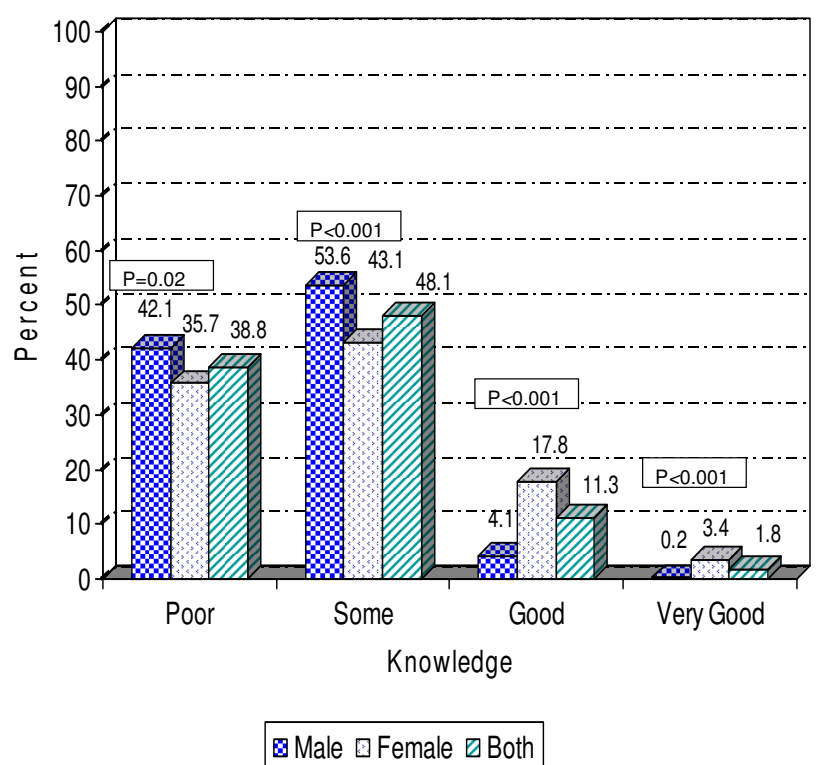

Note: $P$-value (z-test for difference in proportion between males and females at different knowledge levels)

Figure 2

Knowledge level of preventive strategies for HIVI AIDS by sex, $n=1,260$ (males $=605$, females $=655$ ). 


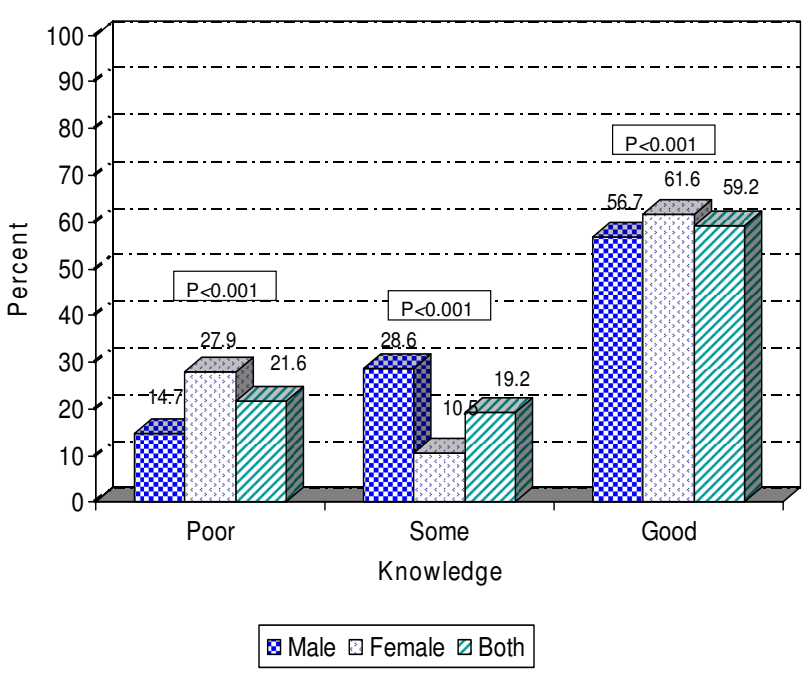

Note: P-value (z-test for difference in proportion between males and females at different knowledge levels)

Figure 3

Summarised knowledge variable and distribution by sex, $n=1,260$ (males $=605$, females $=655)$.

those with "some knowledge" of HIV/AIDS, males performed better than females, even though slightly more females than males were found in the "good knowledge" category. The risk factors analysis supported the wellknown fact that young age and level of education are important, as is socio-economic status. Nevertheless, computer access contributed to acquiring knowledge about HIV/AIDS for the males, while this was not the case for the females. Unmarried females were found to be less well informed than married females.

\section{Methodological considerations}

As this was a cross-sectional study, it is by definition impossible to assess the direction of some of the associations. Poor knowledge about HIV/AIDS is however most probably due to a lack of enrolment at school/college or low educational achievement, as there is a time sequence. The lack of a computer in a household may lead to poor knowledge about HIV/AIDS and, similarly, young age is associated with less knowledge, which is logical.

Three items were designed to assess HIV/AIDS knowledge. One was used only as a pointer (whether HIV is curable), while the other two were open ended and only these were selected for further analysis (modes of spread and preventive strategies) as these items required the respondent to take a stand to formulate an answer, as opposed to when pre-set responses are used. This procedure was judged to sufficiently reflect knowledge and awareness.
If the participant gave at least one accurate response, it was counted as 'correct'. This somewhat liberal attitude might, lead to an overestimation of the level of knowledge and awareness among adolescents, which means that our figures relating to 'poor knowledge' are not inflated.

A multi-stage cluster sampling technique was used to identify the participants, based on stringent criteria. The sample was collected from all over Karachi and randomness was ensured at each step in order to obtain a representative population. However, there were $10-15$ per cent refusals in some of the blocks in the higher socio-economic status areas. This was taken into account by moving to an adjacent household and there is no reason to believe that this changed the representativeness of the study population in terms of socio-economic status, as blocks are fairly homogeneous in this respect.

The interviewers were well versed with the questionnaire and they strictly followed the instruction manual. Furthermore, the field manager scrutinised each form at the field site for completion and good quality of data. However, due to strong religious and cultural beliefs, only questions phrased in a general sense could be asked and issues such as the individuals' own sexual experiences could not be discussed. Despite these constraints, we believe this study was able to identify knowledge and awareness among the young people to benefit the design of appropriate interventions.

As concerns generalisability of our findings, we consider them applicable to urban populations throughout Pakistan, yet the situation is somewhat different in northern parts of the country with in general a lower level of education in the population.

\section{Comparing results with other studies}

In this study population, more males than females reported not having heard about HIV/AIDS (76 per cent). A national survey reported that about 91 per cent of young people had heard of HIV/AIDS in an urban setting [18]. This slightly higher figure was due to the age bracket, which was somewhat higher, up to 24 years.

A study from Chile, investigating knowledge of HIV/AIDS among 15-19 year olds found a different pattern in that no significant differences were found in terms of knowledge of preventive practices related to HIV/AIDS according to either gender or educational level [21]. A study from the United Arab Emirates investigating HIV knowledge among first-year university students found that serious misconceptions existed and women were less knowledgeable than men [2].

It was somewhat surprising to discover that more females than males responded in the affirmative when asked 'have 
Table 4: Association between socio-demographic and psychosocial factors and knowledge of HIVIAIDS.

\begin{tabular}{|c|c|c|c|c|c|c|}
\hline \multirow[b]{2}{*}{$\begin{array}{l}\text { Socio-demographic } \\
\text { Factors }\end{array}$} & \multicolumn{3}{|c|}{ Males $(n=605)$} & \multicolumn{3}{|c|}{ Females $(n=655)$} \\
\hline & $\begin{array}{c}\text { All } \\
N\end{array}$ & $\begin{array}{c}\text { Poor knowledge } \\
n \%\end{array}$ & $\begin{array}{c}\text { Crude OR } \\
95 \% \mathrm{Cl}\end{array}$ & $\begin{array}{c}\text { All } \\
N\end{array}$ & $\begin{array}{c}\text { Poor knowledge } \\
n \%\end{array}$ & $\begin{array}{c}\text { Crude OR } \\
95 \% \mathrm{Cl}\end{array}$ \\
\hline \multicolumn{7}{|l|}{ Age group (years) } \\
\hline$|9-2|$ & 382 & $42(11.0 \%)$ & I & 392 & $92(23.5 \%)$ & 1 \\
\hline $17-18$ & 223 & 47 (21.1\%) & $2.16(1.37,3.40)$ & 263 & $91(34.6 \%)$ & $1.72(1.22,2.44)$ \\
\hline \multicolumn{7}{|l|}{ Years of schooling } \\
\hline$\geq 6$ & 541 & 70 (12.9\%) & I & 541 & $144(26.6 \%)$ & 1 \\
\hline$<6$ & 64 & $19(29.7 \%)$ & $2.84(1.57,5.14)$ & 114 & 39 (34.2\%) & $\mathrm{I} .43(0.93,2.21)$ \\
\hline \multicolumn{7}{|l|}{ Enrolment (school/college) } \\
\hline Yes & 364 & $51(14.0 \%)$ & I & 273 & $65(23.8 \%)$ & 1 \\
\hline No & 241 & $38(15.8 \%)$ & $1.15(0.73,1.81)$ & 382 & $118(30.9 \%)$ & $\mathrm{I} .43(1.01,2.04)$ \\
\hline \multicolumn{7}{|l|}{ Working status } \\
\hline Not working (including students) & 468 & $64(13.7)$ & I & 602 & $168(27.9)$ & 1 \\
\hline Working & 137 & $25(18.2)$ & $\mathrm{I} .4 \mathrm{I}(0.85,2.34)$ & 53 & $15(28.3)$ & $1.02(0.55,1.90$ \\
\hline \multicolumn{7}{|l|}{ Marital status } \\
\hline Ever married & 3 & $0(0.0)$ & - & 94 & $19(20.2 \%)$ & I \\
\hline Unmarried & 602 & $89(14.8)$ & - & 561 & $164(29.2 \%)$ & I.63 $(0.96,2.78)$ \\
\hline \multicolumn{7}{|l|}{ Residential status } \\
\hline Permanent & 455 & $59(13.0 \%)$ & I & 418 & $126(30.1 \%)$ & I \\
\hline Migrant & 150 & $30(20.0 \%)$ & $1.68(1.03,2.72)$ & 237 & 57 (24.1\%) & $0.73(0.5 \mathrm{I}, \mathrm{I} .06)$ \\
\hline \multicolumn{7}{|l|}{ Family type } \\
\hline Extended & 35 & $6(17.1 \%)$ & 1 & 243 & 61 (25.1\%) & 1 \\
\hline Nuclear & 570 & $83(14.6 \%)$ & $0.82(0.33,2.04)$ & 412 & $122(29.6 \%)$ & $1.25(0.88,1.80)$ \\
\hline \multicolumn{7}{|l|}{ Socio-economic status } \\
\hline High to middle & 301 & $42(14.0 \%)$ & I & 294 & $65(22.1 \%)$ & 1 \\
\hline Low & 304 & 47 (15.5\%) & $1.13(0.72,1.77)$ & 361 & 118 (32.7\%) & $1.71(1.20,2.43)$ \\
\hline \multicolumn{7}{|l|}{ Own TV } \\
\hline Yes & 546 & 78 (14.3\%) & I & 610 & $170(27.9 \%)$ & I \\
\hline
\end{tabular}


Table 4: Association between socio-demographic and psychosocial factors and knowledge of HIVIAIDS. (Continued)

\begin{tabular}{lcccccc}
\hline No & 59 & $11(18.6 \%)$ & $1.38(0.68,2.76)$ & 45 & $13(28.9 \%)$ & $1.05(0.54,2.05)$ \\
\hline Own computer & & & & & & \\
\hline Yes & 183 & $17(9.3 \%)$ & 1 & 122 & $36(29.5 \%)$ & 1 \\
\hline No & 422 & $72(17.1 \%)$ & $2.00(1.15,3.52)$ & 533 & $147(27.6 \%)$ & $0.91(0.59,1.40)$ \\
\hline
\end{tabular}

Odds ratios and $95 \%$ confidence intervals, $n=1,260$.

you heard of HIV/AIDS'. This could be explained by the fact that females are more exposed to TV and radio broadcast campaigns about HIV/AIDS, as they spend more time in the home. These campaigns may have some effect in conveying the message [18], but, in this study, access to TV did not indicate any association with deeper knowledge of HIV/AIDS. Having a computer in the home did, however, contribute to improved knowledge among males but not among females. This indicates that, even though there are computers in the homes, the females are not expected to use them. It appears that females are mainly dependent on relatives and peers for knowledge and information about HIV/AIDS, which need further exploration.

When it came to the mode of spread and preventive strategies for HIV/AIDS, a high percentage knew about the source through which the infection could spread, which is quite similar to the findings reported in a national survey [18]. In our study, more males than females named sexual contact as the major mode of spread, while more females than males mentioned used syringes. This finding could be explained by the fact that females are more reluctant to mention sexual matters, while males can talk openly to a stranger (interviewer) about it as a result of the prevailing gender practices in this culture.

When knowledge about HIV/AIDS was assessed on the basis of a composite variable, more females were distributed at either extreme, i.e. more females had a 'poor knowledge' but, at the same time, more females had a 'good knowledge' compared with the males. This dispersion is most probably explained by the vulnerable situa-

Table 5: Association between selected socio-demographic factors and poor knowledge of HIVIAIDS among males and females, presented as adjusted OR and confidence intervals $(95 \% \mathrm{Cl})$, final models, $\mathrm{n}=1,260$.

\begin{tabular}{|c|c|c|}
\hline Socio-demographic factors & Males $(n=605)$ & Females $(n=655)$ \\
\hline \multicolumn{3}{|l|}{ Age (years) } \\
\hline$|9-2|$ & I & I \\
\hline $17-18$ & $2.20(1.38,3.49)$ & $1.74(1.22,2.50)$ \\
\hline \multicolumn{3}{|l|}{ Years of schooling } \\
\hline$\geq 6$ & I & \\
\hline$<6$ & $2.46(1.29,4.68)$ & \\
\hline \multicolumn{3}{|l|}{ Own computer } \\
\hline Yes & 1 & \\
\hline No & $1.88(1.06,3.34)$ & \\
\hline \multicolumn{3}{|l|}{ Residential status } \\
\hline Permanent & 1 & \\
\hline Migrant & $1.23(0.72,2.10)$ & \\
\hline \multicolumn{3}{|l|}{ Socio-economic status } \\
\hline High to middle & & I \\
\hline Low & & $1.54(1.06,2.22)$ \\
\hline \multicolumn{3}{|l|}{ Enrolment school/college } \\
\hline Yes & & I \\
\hline No & & $1.61(1.09,2.39)$ \\
\hline \multicolumn{3}{|l|}{ Marital status } \\
\hline Ever married & & 1 \\
\hline Unmarried & & $1.85(1.05,3.26)$ \\
\hline
\end{tabular}


tion most females have to face with lower school attendance and higher levels of illiteracy among females as compared to males. At the same time, some females, mainly from families with a higher socio-economic status, are given the opportunity to enter into higher education and they perform well.

In some studies conducted in neighbouring India, it was revealed that female adolescents were less knowledgeable about HIV/AIDS compared with male adolescents, while the males reported significantly greater exposure to HIV/ AIDS education compared with the females [22]. Moreover, there was a substantial gap in the knowledge of and attitudes towards HIV/AIDS and other sexually transmitted diseases, but males performed somewhat better than females [23]. Nevertheless having good knowledge about HIV/AIDS does not necessarily translate into healthy behaviours [24].

It was further found that the risk factor profile differed somewhat between the males and the females. These differences are due to women and men living different lives in Pakistan, mainly due to gender disparities. This is specifically evident in terms of access to education [19]. In addition, investment in primary education is higher for males than for females [25]. A recent demographic survey showed that education is positively related to knowledge of HIV/AIDS [26], which supports the findings in this study.

\section{Conclusion}

Our findings suggest that there is a huge need to educate young adults and equip them with sufficient information and skills about HIV/AIDS and to further support them to adopt healthy behaviours to prevent a more widespread epidemic in the general population. This is a matter not only of educating the young people, it also involves a change of attitudes and beliefs to take the final step also to change behaviour. This study is able to show that there are huge gaps in knowledge and awareness and to build a healthy nation the other steps towards changing behaviours also needs attention from policy makers, health staff, the school system and families.

The school system needs to assume responsibility for life skills education of which sexual and reproductive health issues constitute a main part. Though, the young adults who are outside the formal educational system also need to be informed. Community leaders, youth clubs and peers are key people at grass root level.

Taboos surrounding the public discussion of sexuality remain a key constraint to preventive activities. Parents often feel ill equipped to talk to their children, even though they may be young people's preferred source of information, but also school teachers have been mentioned in this respect. Political leaders need to address young people's need for information, education and services, investing in national gender awareness programmes to support the health and development of young people.

However, as the prevalence of HIV/AIDS is still comparatively low, the epidemic has not yet enforced a general discussion on the importance of a well-informed younger generation. More qualitative research, addressing the perceptions of young people themselves, is needed.

The findings from this study will provide input for policy formulation and programme design, addressing adolescents' awareness of HIV/AIDS.

\section{Competing interests}

The authors declare that they have no competing interests.

\section{Authors' contributions}

SFH was the principal investigator and was involved in all steps up to manuscript writing, EJ contributed in the logistics while GK helped in analysis and critical review of the manuscript. All authors have read and approved the final manuscript.

\section{Acknowledgements}

We sincerely wish to thank the participating adolescents for sharing with us the information needed for this study and also the interviewers who collected the data in a professional way. This study was supported by grants from SIDA/Sarec and we are also thankful to the Swedish Institute for support given to the first author.

\section{References}

I. 2008 Report on the global AIDS epidemic [http:// www.unaids.org/en/KnowledgeCentre/HIVData/GlobalReport/2008/ 2008 Global report.asp]

2. Ganczak M, Barss P, Alfaresi F, Almazrouei S, Muraddad A, Al-Maskari F: Break the silence: HIVIAIDS knowledge, attitudes, and educational needs among Arab university students in United Arab Emirates. J Adolesc Health 2007, 40(6):572. e571-578.

3. McManus A, Dhar L: Study of knowledge, perception and attitude of adolescent girls towards STIs/HIV, safer sex and sex education: (a cross sectional survey of urban adolescent school girls in South Delhi, India). BMC Womens Health 2008, 8:12.

4. Surveillance Data. In Sindh AIDS Control Program Government of Sindh, Pakistan; 2004.

5. Shah SA, Altaf A, Mujeeb SA, Memon A: An outbreak of HIV infection among injection drug users in a small town in Pakistan: potential for national implications. Int J STD AIDS 2004, I 5(3):209.

6. Bokhari A, Nizamani NM, Jackson DJ, Rehan NE, Rahman M, Muzaffar R, Mansoor S, Raza H, Qayum K, Girault P, et al.: HIV risk in Karachi and Lahore, Pakistan: an emerging epidemic in injecting and commercial sex networks. Int J STD AIDS 2007, I 8(7):486-492.

7. THE WORLD BANK: HIVIAIDS in Pakistan. 2006 [http://sitere sources.worldbank.org/INTSAREGTOPHIVAIDS/Resources/HIVAIDS-brief-August06-PKA.pdf].

8. Pakistan Demographic Survey 1999. In Federal Bureau of Statistics Statistics Division Govt of Pakistan; 200I.

9. 1998 Census report of Pakistan. Population Census Organization, Statistics Division, Government of Pakistan. Islamabad 2001. 
10. Biddlecom AE, Munthali A, Singh S, Woog V: Adolescents' views of and preferences for sexual and reproductive health services in Burkina Faso, Ghana, Malawi and Uganda. Afr J Reprod Health 2007, I I (3):99-100.

II. Kipp W, Chacko S, Laing L, Kabagambe G: Adolescent reproductive health in Uganda: issues related to access and quality of care. Int J Adolesc Med Health 2007, 19(4):383-393.

12. Meuwissen LE, Gorter AC, Segura Z, Kester AD, Knottnerus JA: Uncovering and responding to needs for sexual and reproductive health care among poor urban female adolescents in Nicaragua. Trop Med Int Health 2006, I I (12): I858-1867.

13. Bastien S, Sango W, Mnyika KS, Masatu MC, Klepp KI: Changes in exposure to information, communication and knowledge about AIDS among school children in Northern Tanzania, 1 992-2005. AIDS Care 2008, 20(3):382-387.

14. Afsar HA, Mahmood MA, Barney N, Ali S, Kadir MM, Bilgrami M: Community knowledge, attitude and practices regarding sexually transmitted infections in a rural district of Pakistan. J Pak Med Assoc 2006, 56 (I Suppl I):S50-54.

15. Ali M, Bhatti MA, Ushijima H: Reproductive health needs of adolescent males in rural Pakistan: an exploratory study. Tohoku J Exp Med 2004, 204(I): 17-25.

16. Ali TS, All PA, Waheed H, Memon AA: Understanding of puberty and related health problems among female adolescents in Karachi, Pakistan. J Pak Med Assoc 2006, 56(2):68-72.

17. Centers for Disease Control and Prevention (CDC): Epi Info. Atlanta $6.04 d$ edition. 2001.

18. Reproductive Health of Youth: Perceptions, Attitudes and Practices. National Institute of Population Studies (NIPS) Pakistan, Islamabad; 2003.

19. Adolescents and Youth in Pakistan: A Nationally Representative Survey 200I-2002. Population Council Pakistan Islamabad; 2003.

20. SPSS Inc 1989-2006 Copyright (c): Statistical package for social sciences. In SPSS 15.0 for windows edition Chicago, USA; Release 15.0.1; 2006.

21. Perez VR, Barrales Cl, Jara PJ, Palma RV, Ceballos MA: Knowledge of HIVIAIDS among adolescents in Chillan, Chile. Midwifery 2008, 24(4):503-508.

22. Pramanik S, Chartier M, Koopman C: HIVIAIDS stigma and knowledge among predominantly middle-class high school students in New Delhi, India. J Commun Dis 2006, 38(I):57-69.

23. Lal SS, Vasan RS, Sarma PS, Thankappan KR: Knowledge and attitude of college students in Kerala towards HIVIAIDS, sexually transmitted diseases and sexuality. Natl Med I India 2000, 13(5):23I-236.

24. Elliot N, Crump J, McGuire A, Bagshaw S, Chambers S: Knowledge, attitudes and behaviour towards HIV infection among family planning clinic attendees: changes between 1991 and I997. $\mathrm{N}$ Z Med I 1999, I I 2(1 085): | $21-123$.

25. Ismail $\mathrm{ZH}$ : Gender differentials in the cost of primary education: a study of Pakistan. Pak Dev Rev 1996, 35(4 Pt 2):835-849.

26. Pakistan Demographic and Health Survey 2006-7. National Institute of Population Studies, Islamabad Pakistan; 2008.

\section{Pre-publication history}

The pre-publication history for this paper can be accessed here:

http://www.biomedcentral.com/1471-2334/9/38/prepub
Publish with Bio Med Central and every scientist can read your work free of charge

"BioMed Central will be the most significant development for disseminating the results of biomedical research in our lifetime. "

Sir Paul Nurse, Cancer Research UK

Your research papers will be:

- available free of charge to the entire biomedical community

- peer reviewed and published immediately upon acceptance

- cited in PubMed and archived on PubMed Central

- yours - you keep the copyright

Submit your manuscript here:

http://www.biomedcentral.com/info/publishing_adv.asp
BioMedcentral 